\title{
Nutritional constraints on egg production in birds
}

\author{
BY DAVID C. HOUSTON \\ Applied Ornithology Unit, Institute of Biomedical and Life Sciences, University of Glasgow, \\ Glasgow GI2 $8 Q Q$
}

The production of eggs can make a major nutritional demand on a female bird. The scale of the required investment varies between species, depending on the size of each egg and the number of eggs laid. For large species, where egg weight is a small proportion of female body mass, the investment in the egg is small, but in some passerines the female will lay a clutch that weighs more than her own body weight. This requires a substantial investment of both energy and nutrients. Robbins (1981) estimated that the daily cost of egg production to wild birds varied between species from $37 \%$ to $216 \%$ of normal daily energy metabolism and from $86 \%$ to $230 \%$ of daily protein requirements.

There is an extensive literature on the nutrients required for egg formation in domestic poultry and how these are obtained. But we know little about this process in wild birds. The findings on egg production from poultry research have little relevance to wild birds for the obvious reason that domestic poultry have been selectively bred to lay about one egg every day for the whole of their productive life. To sustain this remarkable scale of egg production it is obvious that the daily food intake must provide all nutritional requirements for egg formation. Body reserves could not make any substantial contribution, but can act as a temporary storage pool over a $24 \mathrm{~h}$ cycle to regulate delivery of ingested nutrients, as is known to occur for the Ca used in shell formation (Scott et al. 1982). In wild birds, egg production is an unusual, and critically important, event in the annual cycle of the bird. The resources for egg formation could come from three routes: through increased food intake, the use of body reserves, or metabolic changes in the female to permit a re-allocation of resources from body maintenance to egg formation. The relative importance of these various routes has still not been determined for any species of wild bird (Walsberg, 1983; Houston et al. 1995a). The present paper first reviews whether there is any evidence that nutrient availability, and particularly essential amino acids, might constrain egg production in wild birds. It then considers whether some birds may use endogenous reserves to assist with the provision of limiting nutrients. Finally it considers the implications of these findings for the captive breeding of some bird species.

\section{NUTRITIONAL CONSTRAINTS ON EGG FORMATION IN WILD BIRDS}

Lack (1967) first proposed that birds time their breeding season so that the period when the young are growing most actively in the nest, which is when the parents need to find most food, should coincide with the season of maximum food availability in the year. A consequence of this may be that to achieve this timing the parents need to lay their eggs several weeks before the time of peak food abundance, when food may be far less plentiful (Perrins, 1970). This raises the possibility that food supply at the time of egg laying may be inadequate, and limit egg production. A number of studies do show a clear relationship between egg production and the size of the food supply; for example, Perrins (1991) showed that in a population of great tits (Parus major), there was a clear correlation between the number of eggs laid and the abundance of caterpillars, their main food supply (Fig. 1). However, as Perrins (1991) and other authors suggest, there could be other 
explanations for this correlation. Birds might be adjusting the number of eggs they lay not because the amount of food is limiting the number of eggs they can produce, but because they are responding to cues in the environment which indicate how large the food supply will be later in the season when the young are in the nest, and modifying their clutch so that it reflects the number of young they are likely to be able to rear. A number of studies have attempted to distinguish between these causes by experimentally manipulating the food supply of birds in the wild by providing additional food at the time of egg production. The results of these studies have been varied (for reviews, see Arcene \& Smith, 1988; Nager et al. 1997). They generally show that birds provisioned with an additional food supply show a small advancement in the date of laying, but an increase in the clutch size occurs less frequently. Few studies have examined egg size, but where this has been recorded there has usually been little change. There is no consistent evidence that food supply is limiting the quantity of eggs a bird can lay.

There are, however, a number of problems in interpreting these various supplementary feeding studies (for reviews, see Bolton et al. 1992; Nager et al. 1997). Among these are differences between studies in the time at which food was provided in relation to the egg formation process, and variation in the type of food given. The underlying assumption behind most supplementary food experiments has been that it is the energy supply which might be limiting egg production, and few studies have considered the nutritional quality of food used for the experimental supplementation. However, there may be essential nutrients required for egg formation that some species find limiting in their normal diets, and that it is these rather than energy which restrict egg laying. There could be dietary limitation for many nutrients, such as vitamins, trace minerals, or essential fatty acids; but perhaps the most likely are certain essential amino acids. This is because it is known that the amino acid balance of egg proteins differs from that of most animal and plant proteins. Fig. 2 shows data for zebra finches (Taeniopygia guttata) and compares the amino acid requirements for the laying of a clutch of four eggs with the amino acid intake by the female bird during the $7 \mathrm{~d}$ period over which her egg production occurs. The balance of amino acids in the dietary protein is different from that required for egg proteins, and for cysteine, even if the entire dietary intake were exclusively used for egg production, it

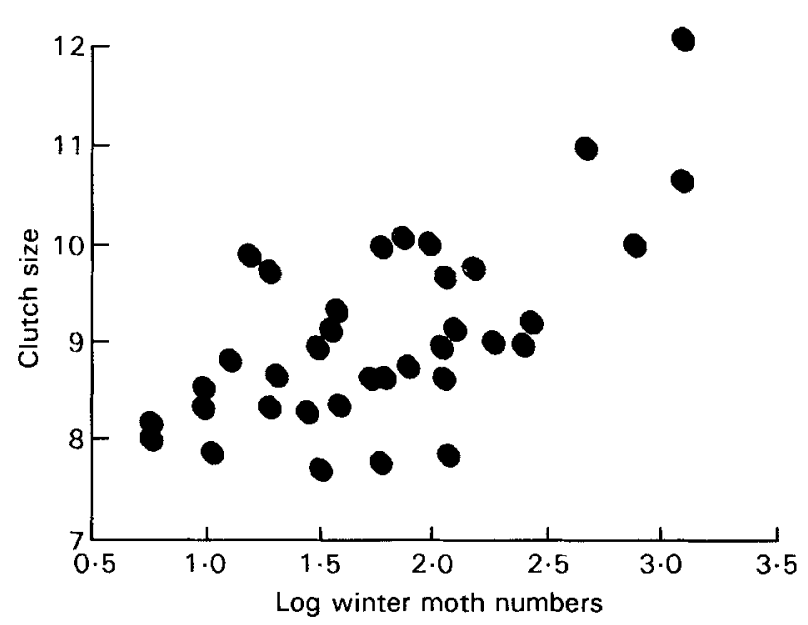

Fig. 1. The correlation between the clutch size of the great tit (Parus major) and the abundance of their main food supply, winter moth caterpillars. (From Perrins, 1991.) 


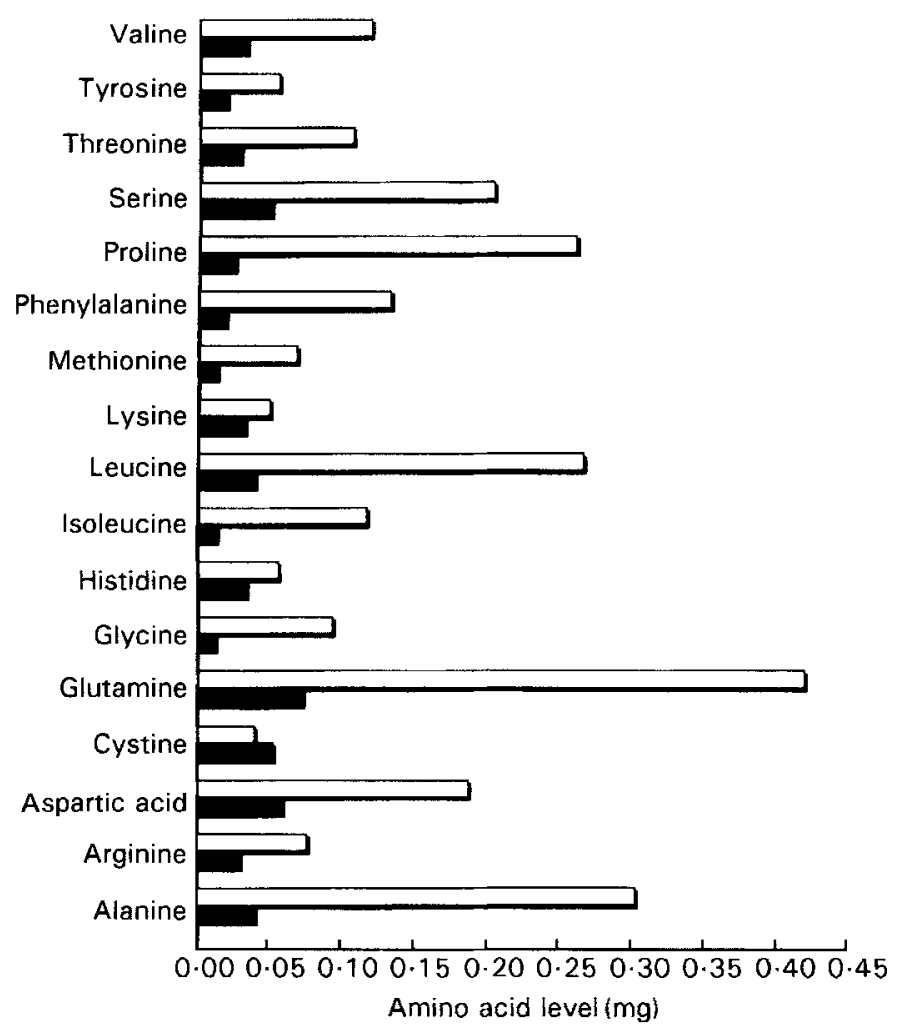

Fig. 2, Comparison of the total amino acid requirements for a four-egg clutch ( $\boldsymbol{\square}$ ) of zebra finch (Taeniopygia guttata) eggs with the total amino acid consumption from the seed diet $(\square)$ during the $7 \mathrm{~d}$ period over which the eggs are formed. (From Houston et al. 1995b.)

would still only meet $76 \%$ of requirements. Murphy (1994), in a review of the amino acid requirements for egg production, concluded that for birds feeding on plant proteins the $S$ amino acids and lysine were most likely to be limiting. It is well known in poultry that when diets are enhanced by these amino acids they result in greater egg production (Fisher, 1976).

Is there any evidence that dietary quality does influence egg production in other birds? In zebra finches there is no doubt. Birds fed on a seed diet will lay significantly smaller clutches than birds fed on a mixture of a seed diet and a commercially-available highprotein feed supplement containing soyabean meal (Haiths \& Co., Cleethorpes; Fig. 3). This is not surprising, considering that seed has been shown to be an inadequate-quality diet for egg production. Is there any evidence that wild birds which feed on high-quality animal-protein diets may be nutritionally constrained? Bolton et al. (1992) carried out supplementary feeding trials on lesser black-backed gulls (Larus fuscus). Birds were provided with the supplementary food during the period before and during laying, when the females were undergoing ova enlargement. The food was provided late in the evening on the edge of the nest, which ensured that the breeding birds consumed the food, and this method prevented stealing of food by neighbouring pairs. Food was provided in two forms. Some birds were given a block of animal fat, which would chiefly act as an energy supplement. Other birds were given a piece of fish, of the same energy value as the fat supplement, which would act as a supplement for protein as well as energy. If energy 


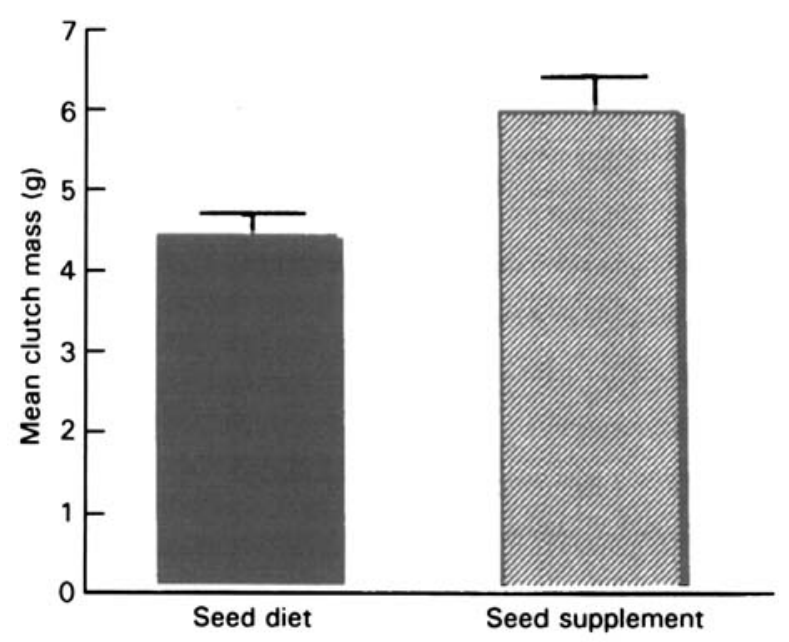

Fig. 3. Mean clutch mass for zebra finches (Taeniopygia guttata) fed on a seed diet and those on a seed diet with a supplement of higher protein content ( $n 22$ and 24 respectively). Values are means with 1 SE represented by vertical bars.

supply was limiting egg formation we would expect both groups to show the same enhanced egg production compared with the control group. The results (Fig. 4(a)) showed that the fat-fed birds did not lay larger eggs, but that birds fed on the fish supplement did lay significantly larger eggs.

Bolton et al. (1992) then compared the egg-laying performance of two groups of gulls, one fed on the fish-supplemented diet and the other given cooked hens' eggs, again both groups received food of equivalent energy value and equivalent protein content. The assumption was that if overall protein availability were the limiting factor, then both
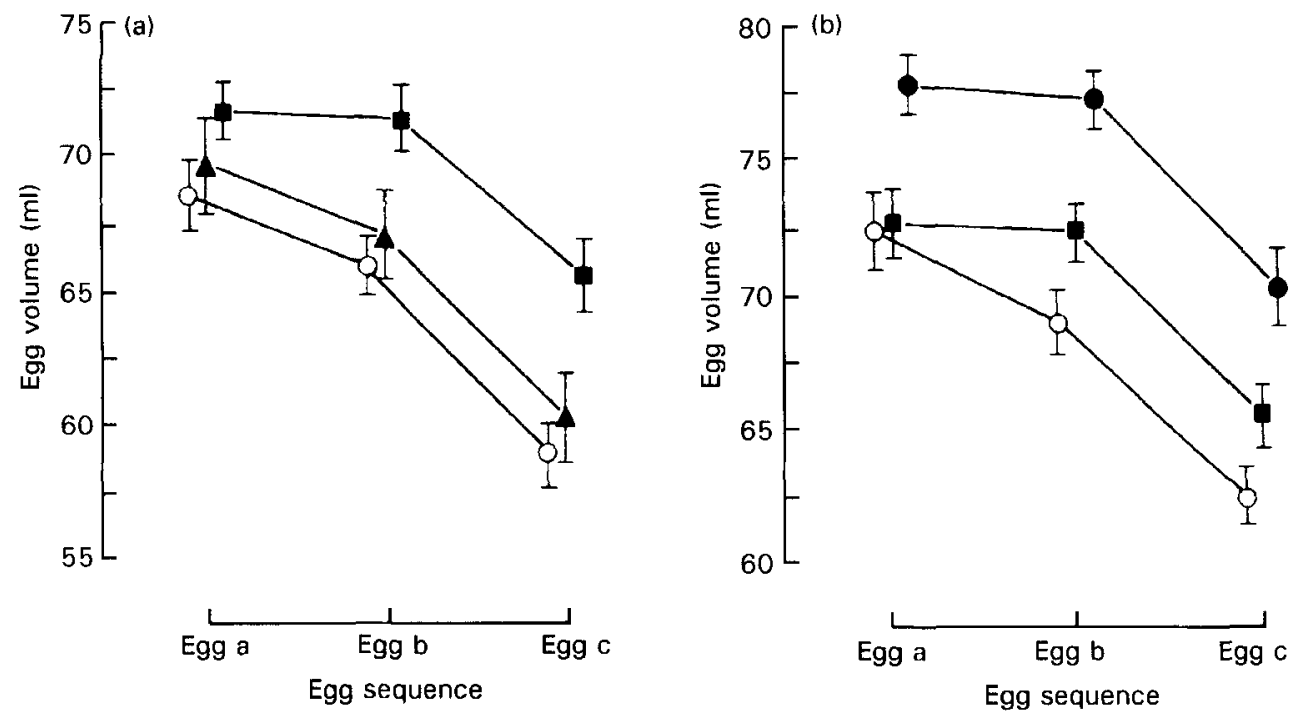

Fig. 4. (a) Mean egg volume of eggs from three-egg clutches of lesser black-backed gulls (Larus fuscus) laid by control birds $(O)$, birds fed on a fish supplement $(\square)$ and birds fed on a fat supplement ( $\boldsymbol{\Delta})$. (b) Mean egg volume of eggs from three-egg clutches of lesser black-backed gulls laid by control birds $(O)$, birds fed on a fish supplement ( $(\mathbf{)})$ and birds fed on an egg supplement (-). Points are means with 1SE represented by vertical bars. (From Bolton et al. 1992.) 
groups should respond in a similar manner. However, if some aspect of protein quality were involved, then we might expect the egg-supplemented birds to show greater egg production, based on the assumption that the balance of amino acids required for egg formation will be met by a diet of cooked eggs, whilst the amino acid balance in fish protein will be less balanced for egg-protein production. Fig. 4(b) shows that the egg-fed birds showed significantly greater egg production than birds fed on the fish protein. We do, however, need to be cautious in interpreting these results in terms of protein differences, because there could be many other explanations for these findings. Clearly the egg and fish diets will differ in many aspects of their nutritional content, and we cannot assume that it was amino acid balance alone that led to these results. To demonstrate that protein quality is the deciding factor we need to supplement with specific amino acids, and we have done this with a study of blue tits (Parus caeruleus). Fig. 5 shows that in tits, as in gulls, it is the diet quality, not energy availability, which limits egg production, because birds given a supplement of egg proteins produced significantly more eggs than those given a supplement of animal fat (Ramsay \& Houston, 1997). Recent supplementary feeding trials have been carried out using blue tits in which birds were provided with supplementary food which differed in only five amino acids, these being selected as being those most likely to be limiting in the environment. A control group was given an identical diet, balanced for $\mathrm{N}$ content by the supplementation of an equivalent amount of glutamic acid. The results showed that only the birds given the diet with presumed limiting amino acid balance showed significantly enhanced egg production. Thus, we conclude that in this case it was protein quality which caused these effects (Ramsay \& Houston, 1997).

These results are perhaps rather surprising. Murphy (1994) suggested that there might be an imbalance in amino acid intake for egg production in bird species which feed largely on plant foods, some of which have relatively low protein levels, and where the proteins generally have a more marked imbalance in amino acid composition than that of general animal proteins. But she concluded that most bird species should not face these problems because their overall protein intake is high enough to overcome any small imbalances in

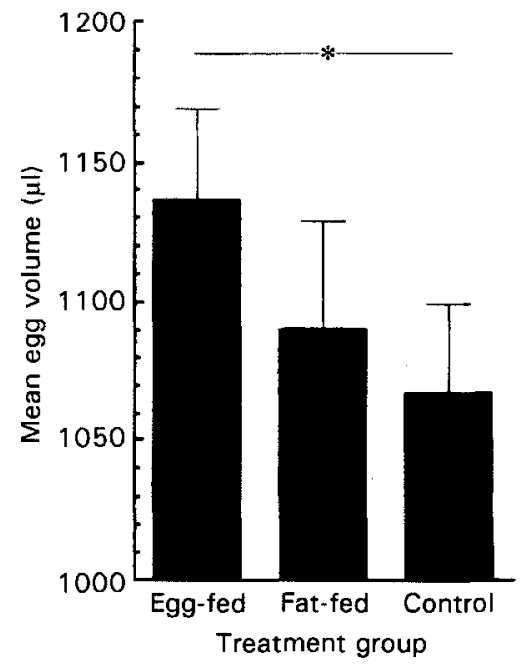

Fig. 5. Mean egg volume of blue tit (Parus caeruleus) eggs laid by control birds, birds fed on a lipid supplement and birds fed on an egg supplement. Values are means with 1SE represented by vertical bars. (From Ramsay \& Houston, 1997.) Significance of pairwise comparisons indicated; ${ }^{*} P<0.05$. 
certain amino acids. Blue tits, according to the literature, feed entirely on animal protein. However, their protein intake may be lower than is generally realized. First, tits are feeding largely on caterpillars at this time of year, and it is often assumed that these are largely animal protein. In fact, $20-25 \%$ of the weight of a caterpillar is composed of gut contents of crushed leaves (S. L. Ramsay, personal communication). Second, birds in the wild often make surprisingly marked shifts in diet at specific times of the annual cycle, which at the moment we do not understand. Tits make one such shift at the time they are forming eggs. Betts (1955) found that about $30 \%$ of the stomach contents of tits at laying time was composed of the leaf buds of oak trees (Quercus robur and Quercus petraea), and in some individuals it was more than $50 \%$. Quite why there should be such a high proportion of plant-leaf material consumed at this time is not clear. Betts (1955) suggested that the birds may be feeding on insects living within the swelling tree buds and the plant material is swallowed by accident. However, tits are so dexterous in the use of their bill to manipulate food that I find it difficult to believe they could not separate insect grubs from the surrounding plant tissue. It may be that there are specific nutrients available in plant leaf buds which cause the birds to seek them out at the time of egg formation. Whatever the reason, it further reduces the daily intake of animal protein and, thus, it would be more accurate to describe the food of a tit as being more than $50 \%$ herbivorous at egg-laying time. Finally, tits need to seek out Ca-rich food items on the day before each egg is laid in order to obtain sufficient $\mathrm{Ca}$ for shell formation (Graveland \& van Gijzen, 1994). In areas of low $\mathrm{Ca}$ availability this occupies a considerable period of time, which restricts the length of time available for normal foraging. For all these reasons, it may be misleading to take the normal daily intake of caterpillars by a tit outside the breeding season and assume that this represents the actual daily intake of animal protein at the time of egg formation. Actual intake of insect protein at laying may be considerably lower than such estimates would imply, and might explain why protein limitation on egg formation can occur even in an insectivorous species.

\section{THE ROLE OF BODY RESERVES IN EGG FORMATION}

If there are certain essential amino acids that may be limiting in the diet, there would be strong selective pressure on birds to develop mechanisms which would allow them to use endogenous sources for egg formation; in this way, female birds which had good reserves would be able to lay larger eggs and larger clutches than the food supply would permit. The muscle system is the largest mass of protein in the body, and perhaps the most likely to act as a protein source. Jones \& Ward (1976) in a study on red billed quelea (Quelea quelea) were the first to describe a marked decline in muscle weight at the time of egg formation, and to speculate that the purpose of this protein loss might be to contribute to egg-protein formation (Kendall et al. 1973). The changes which occur in body condition during egg laying have now been studied in about twenty-nine bird species, and in twenty-one of these there is a significant loss of muscle tissue at the time eggs are forming (Houston et al. $1995 \mathrm{c}$ ). The use of labelled amino acids has shown that there is an enhanced loss of amino acids from muscle tissue in laying birds, and that these are used in the formation of egg proteins (Houston et al. 1995a). Houston et al. (1995c) showed in zebra finches that there is a significant loss of both water-soluble and myofibrillar proteins during egg formation, and that, of the sarcoplasmic proteins, there was preferential loss of certain high-molecularweight proteins. It is unlikely that general muscle proteins would be routinely used for egg production, because this might impair muscle contraction and so weaken flight performance. Bird muscle might contain certain proteins, rich in those essential amino 
acids which are limiting in the diet, and which can be mobilized to assist in egg formation. That such a mechanism exists is strongly suggested by some feeding trials we have conducted using zebra finches. Selman \& Houston (1996a) compared the breeding performance of two groups of female birds which differed only in the quality of diet they had experienced before pairing. One group received a high-quality-protein diet which was likely to enable limiting amino acids to be incorporated into muscle, the other group was given a lower-quality-protein diet with lower concentrations of amino acids which were likely to be limiting. After 2 weeks on these diets, the two groups did not differ in body weight or in muscle mass (determined by a non-invasive body-moulding technique; Selman \& Houston, 1996b). When they were paired with a male and allowed to breed, both groups were maintained on identical diets of seed. During the period of egg laying the two groups did not differ significantly in their food intake. However, Fig. 6(a) shows that birds which had previous experience of high-quality diets laid almost twice the weight of eggs, and when this was combined with subsequent rearing success, the females who had had high-quality-diet experience raised three times as many young as those who had experienced low-quality diets. Furthermore, the high-quality-diet females had lost significantly less muscle tissue per $\mathrm{g}$ egg protein produced than the low-quality-protein group (Fig. 6(b)). This is perhaps because birds exposed to high-quality diets might have been able to store specific proteins rich in limiting amino acids. Birds which had not experienced high-quality diets, and which lacked large protein stores, would need to break down a larger quantity of general muscle proteins to permit egg production and, therefore, finished laying in worse muscle condition. Whatever the mechanism, this trial shows that the quality of diet a bird receives well before the start of the breeding season can have a profound effect not only on her egg production, but also on her body condition after laying and, therefore, presumably on her survival prospects. We cannot, of course, assume that all birds rely on body reserves as extensively for egg production as does the zebra finch (Houston et al. 1995b). Drent \& Daan (1980) and Ankney \& Alisauskas (1991) point out that the extent to which a species depends on endogenous reserves will vary with many factors, especially the quality of its diet. However, there has been very little investigation
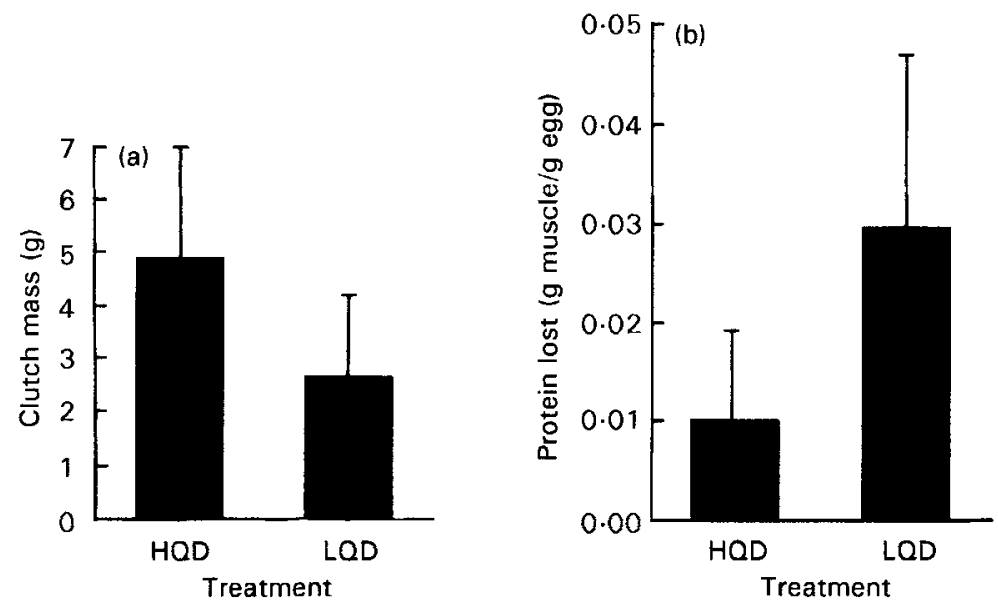

Fig. 6. (a) Comparison of the clutch masses laid by female zebra finches (Taeniopygia guttata) which had received highquality diets (HQD) and low-quality diets (LQD) during the period before pairing, and (b) comparison of the loss of lean, dry pectoral muscle tissue perg egg laid by the two female groups. Values are means with 1SE represented by vertical bars. (From Selman \& Houston, 1996b.) 
of dietary quality as a limitation on egg production, and this may act to a greater extent and in a wider range of species than has previously been realized.

\section{IMPLICATIONS FOR CAPTIVE BREEDING OF BIRDS}

It is generally acknowledged that great care needs to be given to the nutritional balance of bird diets when they are rearing young. The quality of diet a bird receives before laying can also have a profound influence on breeding success, not only in the immediate period when eggs are being formed, but also mediated via the body condition of the female bird which has been established perhaps over several months before the start of the breeding season. If we accept that endogenous reserves are important in egg production, then to bring birds into peak breeding condition it would seem sensible to consider the protein quality of their normal diet and compare this with the amino acid balance required for egg formation (the eggs of birds differ very little between species in their amino acid balance; Murphy, 1994). This may require a different diet from that which would otherwise be adequate to maintain them in good health. This might highlight aspects of the diet which may be inadequate and where the diet needs supplementation. Two general points should be considered, which are contradictory. The first is a common assumption that birds will, if given sufficient choice, have the ability to select the right nutritional balance in their diet. Murphy (1993) has shown that birds have a limited ability to discriminate between diets which differ in important nutrients, but birds may not be able to do this to a sufficient extent to select a diet which results in maximum egg production. Second, in the wild, birds have the opportunity to take a far greater diversity of food items than is available in most captive situations, and it is well known that birds will make surprisingly large diet changes at specific times during the year. These may be associated with the need for specific nutrients; e.g. birds seek Carich food items only when needing to form eggshells. In captivity, where they usually have a restricted range of food, they do not have this option, and are dependent on being provided with diets which have been based on a good dietary analysis of all their likely requirements. In the design of breeding programmes it may be useful to give more attention to the nutritional requirements for egg formation and ensure that these are represented in the diet both in the pre-breeding period as well as during the time of egg formation itself.

I am grateful to Peter Jones, Pat Monaghan, Dan Osborne, Ian Hamilton, Mark Bolton, David Donnan, Richard Selman, and Scot Ramsay who collaborated in the work outlined here. Most of the projects were funded by the Natural Environment Research Council.

\section{REFERENCES}

Ankney, C. D. \& Alisauskas, R. T. (1991). The use of nutrient reserves by breeding waterfowl. Proceedings of the International Ornithology Congress 20, 2170-2176.

Arcene, P. \& Smith, J. N. M. (1988). Effects of population density and supplemental food on reproduction in song sparrows. Journal of Animal Ecology 54, 119-136.

Betts, M. M. (1955). The food of titmice in oak woodland. Journal of Animal Ecology 24, 282-323.

Bolton, M., Houston, D. C. \& Monaghan, P. (1992). Nutritional constraints on egg formation in the lesser blackbacked gull: an experimental study. Journal of Animal Ecology 61, 521-532.

Drent, R. H. \& Daan, S. (1980). The prudent parent: energetic adjustment to avian breeding. Ardea 68, $225-331$.

Fisher, C. (1976). Protein in the diets of the pullet and laying bird. In Protein Metabolism and Nutrition, pp. 323-352 [D. J. A. Cole, K. N. Boorman, P. J. Buttery, D. Lewis, R. J. Neale and H. Swan, editors]. London: Butterworths.

Graveland, J. \& van Gijzen, T. (1994). Arthropods and seeds are not sufficient as calcium sources for shell formation and skeletal growth in passerines. Ardea 82, 299-314. 
Houston, D. C., Donnan, D. \& Jones, P. J. (1995a). Use of labelled methionine to investigate the contribution of muscle proteins to egg production in zebra finches. Journal of Comparative Physiology 165B, 161-164.

Houston, D. C., Donnan, D. \& Jones, P. J. (1995b). The source of the nutrients required for egg production in zebra finches Poephila gullata. Journal of Zoology, London 235, 469-483.

Houston, D. C., Donnan, D., Jones, P. J., Hamilton, I. \& Osborne, D. (1995c). Changes in the muscle condition of female zebra finches during egg laying and the role of protein storage in bird skeletal muscle. Ibis 137, 322-328.

Jones, P. J. \& Ward, P. (1976). The level of reserve protein as the proximate factor controlling the timing of breeding and clutch size in the Red-billed Quelea. Ibis 118, 547-574.

Kendall, M. D., Ward, P. \& Bacchus, S. (1973). A protein reserve in the pectoralis major flight muscle of Quelea quelea. Ibis 115, 264-270.

Lack, D. (1967). The Natural Regulation of Animal Numbers. Oxford: Oxford University Press.

Murphy, M. E. (1993). Dietary amino acid complementation as a foraging strategy for wild birds. Physiology and Behavior 53, 689-698.

Murphy, M. E. (1994). Amino acid compositions of avian eggs and tissues: nutritional implications. Journal of Avian Biology 25, 27-38.

Nager, R. G., Rüegger, C. \& van Noordwijk, A. J. (1997). Nutrient or energy limitation on egg formation: a feeding experiment in great tits Journal of Animal Ecology 66, 495-507.

Perrins, C. M. (1970). The timing of birds' breeding seasons. Ibis 112, 242-255.

Perrins, C. M. (1991). Tits and their caterpillar food supply. Ibis 133, Suppl., 49-54.

Ramsay, S. L. \& Houston, D. C. (1997). Nutritional constraints on egg production in the blue tit: a supplementary feeding study. Journal of Animal Ecology (In the Press).

Robbins, C. T. (1981). Estimation of the relative protein costs of reproduction in birds. Condor 83, $177-179$.

Scott, M. L., Nesheim, M. C. \& Young, R. J. (1982). Nutrition of the Chicken. Ithaca, New York: Cornell University.

Selman, R. G. \& Houston, D. C. (1996a). The effect of prebreeding diet on reproductive output in Zebra Finches. Proceedings of the Royal Society, London 163B, 1585-1588.

Selman, R, G. \& Houston, D. C. (1996b). A technique for measuring lean pectoral muscle mass in live small birds. Ibis 138, 348-350.

Walsberg, G. E. (1983). Ecological energetics: what are the questions? In Perspectives in Ornithology, pp. 135158 [A. H. Bush and G. A. Clark, editors]. Cambridge: Cambridge University Press. 